\title{
PERENCANAAN STRUKTUR BANGUNAN ATAS JEMBATAN RANGKAS PANJANG KECAMATAN KRAGILAN KABUPATEN SERANG
}

\author{
M. Ichwanul Yusup ${ }^{1}$ dan Bambang Hariyanto ${ }^{2}$ dan $_{\text {Mulyadi }}^{3}$, \\ 1, 2, ${ }^{3}$ Program Studi Teknik Sipil, Universitas Banten Jaya, Jl. Raya Ciwaru II No. 73 Kota Serang Banten \\ Email: ichwanulyusup@yahoo.com \\ Email: bambanghariyanto@unbaja.ac.id \\ Email:maudynaaugust@gmail.com
}

\begin{abstract}
ABSTRAK
Jembatan merupakan salah satu komponen prasarana transportasi darat, yang berfungsi untuk mengatasi rintangan/hambatan alam buatan. Oleh karena itu pada suatu wilayah umumnya terdapat jembatan yang berfungsi sebagai bagian/komponen dan sistem jaringan jalan. Sebagai bahan penting dari sistem infrastruktur di suatu wilayah, maka keberadaan jembatan senantiasa perlu mendapatkan perhatian agar kinerja dan umur layanannya maksimal mungkin dapat dipertahankan, setidak-tidaknya sesuai dengan yang direncanahkan. Perencanaan struktur terdiri dari slab lantai, lapis aspal, genagan air hujan, girder baja, jalur, trotoar, lebar dan bentang. Perencanaan struktur mengacu pada pada RSNI T-12-2004 (Standar Perencanaan Pembebanan Jembatan). Data primer dan data sekunder dari hasil informasi yang didapatkan secara langsung maupun tidak langsung disajikan dalam dua macam bentuk yaitu perhitungan dan gambar-gambar penunjang untuk perencanaan struktur bangunan atas jembatan. Berdasakan hasil dari analisis Perencanaan Struktur Bangunan Atas Jembatan Rangkaspanjang diperoleh hasil perencanaan dengan dimensi tebal slab lantai jembatan direncanakan tebal $0,25 \mathrm{~m}$, tebal lapis aspal direncanakan tebal $0,05 \mathrm{~m}$, tebal genagan air hujan direncanakan tebal $0,05 \mathrm{~m}$, jarak antara girder baja direncanakan 1,60 m, lebar jalur lalu lintas direncanakan $5,50 \mathrm{~m}$, lebar trotoar direncanakan tebal 1,00 m, lebar total jembatan direncanakan 7,50 $\mathrm{m}$ dan panjang jembatan direncanakan bentang 30,00 m
\end{abstract}

Kata Kunci: Jembatan, perencanaan, struktur bangunan atas.

\begin{abstract}
The bridge is one of the components of land transportation infrastructure, which functions to overcome artificial natural obstacles. Therefore, in an area generally there is a bridge that functions as part / component of the road network sistem. As an important ingredient of the infrastructure sistem in an area, the existence of bridges always needs attention so that their maximum performance and service life can be maintained, at least as planned. Structural planning consists of floor slabs, asphalt layers, rainwater puddles, steel girders, paths, sidewalks, widths and spans. Structural planning refers to RSNI T-12-2004 (Bridge Load Planning Standard). Primary data and secondary data from the information obtained directly or indirectly are presented in two forms, namely calculations and supporting drawings for the design of the structure of the bridge. Based on the results of the analysis of the Rangkas Panjang Bridge Upper Building Structural Planning, it was obtained the planning results with the dimensions of the thickness of the slab floor of the bridge was planned to be $0.25 \mathrm{~m}$ thick, the thickness of the asphalt layer was planned to be $0.05 \mathrm{~m}$ thick, the thickness of the rainwater pool was planned to be $0.05 \mathrm{~m}$ thick, the distance between the girders. steel is planned to be $1.60 \mathrm{~m}$, the width of the traffic lane is planned to be $5.50 \mathrm{~m}$, the width of the sidewalk is planned to be $1.00 \mathrm{~m}$ thick, the total width of the bridge is planned to be $7.50 \mathrm{~m}$ and the length of the bridge is planned to be a span of $30.00 \mathrm{~m}$
\end{abstract}

Keywords: Bridge, planning, upper structure 


\section{PENDAHULUAN}

Jembatan merupakan salah satu komponen prasarana transportasi darat, yang berfungsi untuk mengatasi rintangan/hambatan alam buatan. Oleh karena itu pada suatu wilayah umumnya terdapat jembatan yang berfungsi sebagai bagian/komponen dan sistem jaringan jalan. Sebagai bahan penting dari sistem infrastruktur di suatu wilayah, maka keberadaan jembatan senantiasa perlu mendapatkan perhatian agar kinerja dan umur layanannya maksimal mungkin dapat dipertahankan, setidak-tidaknya sesuai dengan yang direncanahkan.

Jembatan mempunyai arti penting bagi setiap orang. Dengan tingkat kepentingannya berbeda-beda bagi setiap pihak menjadikan jembatan sebagai bahan studi yang menarik. Suatu jembatan tunggal di atas sungai kecil memiliki makna yang berbeda bagi tiap orang. Seseorang yang melintasi jembatan tiap hari pada saat pergi bekerja, hanya dapat melintasi sungai bila ada jembatan, dan ia menyatakan bahwa jembatan adalah sebuah jalan yang diberi sandaran pada tepinya. Tentu saja seorang pemimpin pemerintahan dan dunia bisnis akan memandang hal yang berbeda pula.

Bila lebar jembatan kurang lebar untuk menampung jumlah jalur yang diperlukan oleh lalu lintas, jembatan akan menghambat laju lalu lintas. Dalam hal ini jembatan akan menjadi pengontrol volume dan berat lalu lintas yang dapat dilayani oleh sistem transportasi. Oleh karena itu, jembatan dapat dikatakan mempunyai fungsi keseimbangan (balancing) dari sistem tarnsportasi.

Jembatan Rangkaspanjang Kecamatan Kragilan Kabupaten Serang merupakan jalan alternatif dari wilayah Kabupaten Serang menuju wilayah Kabupaten Pandeglang, guna mempercepat waktu perjalanan menuju daerah Panimbang dan sekitarnya, maka Dinas Pekerjaan Umum dan Penataan Ruang (DPUPR) Kabupaten Serang membangun akses prasarana Jembatan Rangkas Panjang Kecamatan Kragilan Kabupaten Serang yang sampai saat ini masih dalam tahap pembangunan, Pembangunan Jembatan Rangkas Panjang Kecamatan Kragilan Kabupaten Serang.

\section{METODE PENELITIAN}

\subsection{Lokasi Penelitian}

Lokasi penelitian berada di Kecamatan Kragilan, Kabupaten Serang, Banten. Tepatnya di Jembatan Rangkaspanjang Kecamatan Kragilan Kabupaten Serang

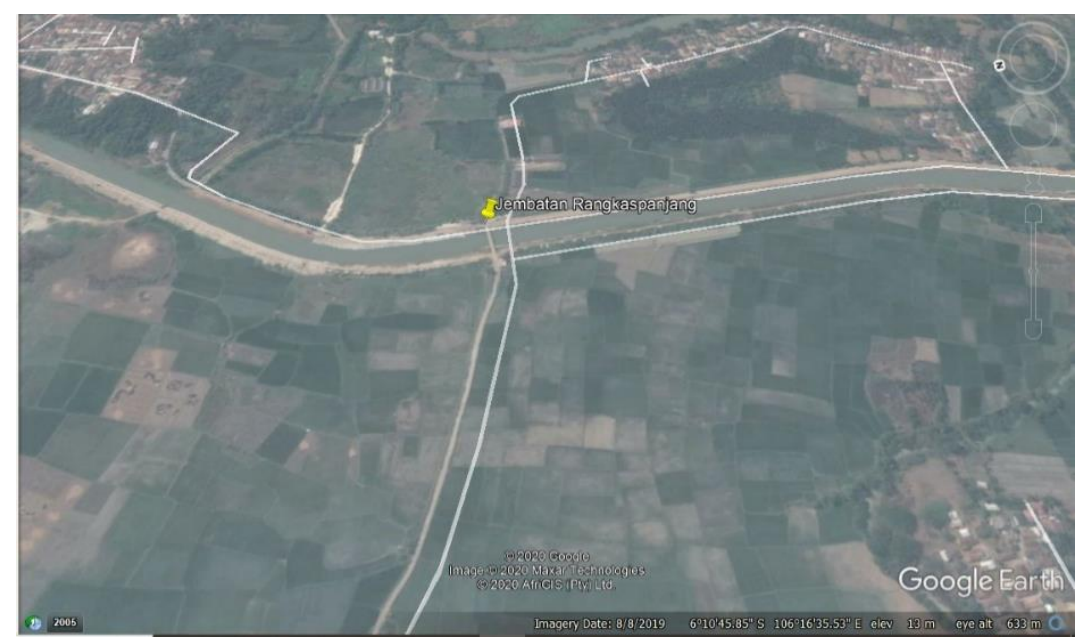

Sumber: Google Earth Pro 6 $10^{\circ} 34.28^{\prime \prime}$ S 106 $16^{\circ} 50.95^{\prime \prime} \mathrm{E}$

Diakses tanggal 8 Juli 2020

Gambar 1. Lokasi penelitian

\subsection{Data Penelitian}

\subsubsection{Metode Data Primer}

Metode yang diperoleh secara langsung oleh penulis dilapangan dengan cara wawancara dan mengamati serta menanyakan perancangan konstruksi kepada pihak-pihak terkait yang ada dilingkungan Paket Pekerjaan Jembatan Rangkaspanjang Kecamatan Kragilan Kabupaten Serang. 


\subsubsection{Metode Data Sekunder}

Data sekunder yang diperoleh penulis dari DED Konsultan Perencana. Merupakan sumber yang sudah ada data-data sekunder, peta lokasi, jadwal pelaksanaan pekerjaan, cross section dan shop drawing.

\subsubsection{Metode Observasi}

Metode observasi ini dilakukan dengan cara mengamati dan memperhatikan langsung dilapangan baik secara langsung maupun tidak langsung. Hal ini dilakukan untuk mengetahui kondisi aktual pada saat sekarang agar tidak terjadi kesalahan dalam perencanaan

\subsection{Perkembangan Jembatan}

Dapat dikatakan bahwa sejarah jembatan sejalan dengan waktu sejarah peradaban manusia. Akan tetapi keberhasilan di bidang teknik jembatan bukan berarti suatu hal yang mudah untuk seperti saat ini. Jembatan sebagaimana bidang keteknikan lainnya khususnya teknik struktur, diawali dengan proses cut and try atau juga dikenal dengan proses try and fail. Sebagai awalnya digunakan metode empiris. Seperti dikatakan oleh Supriyadi (2000) bahwa lima tipe jembatan yang dikenal saat ini berupa balok (beam), kantilever (cantilever), pelengkung (arch) kabel gantung (suspension) dan rangka (truss) untuk empat tipe pertama diilhami dari kehidupan sebelum masehi.

Contoh alami dari jembatan balok sederhana (simple beam bridge) adalah pohon yang tumbang atau ditumbangkan melintas di atas sungai. Perkembangan selanjutnya digunakan slab-slab batu alam sebagai jembatan. Seperti telah disebutkan di atas bahwa kemajuan pengetahuan dan teknologi jembatan sejalan dengan kemajuan peradaban manusia. Dari penjelasan tentang runtutan perkembangan jembatan, dapat diklasifikasikan beberapa struktur atas jembatan yang telah berkembang hingga saat ini, seperti dapat diuraikan sebagai berikut:

1. Jembatan lengkung-batu (stone arch bridge)

Jembatan pelengkung (busur) dari bahan batu, telah ditemukan pada masa lampau, dimasa Babylonia. Namun seiring dengan waktu tipe jembatan ini mulai ditinggalkan.

\section{Jembatan rangka (truss bridge)}

Jembatan rangka dapat terbuat dari naham kayu atau logam. Jembatan rangka kayu (wooden truss) termasuk tipe klasik. Jembatan rangka kayu, hanya terbatas untuk mendukung beban yang tidak terlalu besar. Pada perkembangannya bentuk jembatan ini mengalami kemajuan pesat setelah ditemukannya rangka baja.

\section{Jembatan gantung (suspension bridge)}

Dengan kemajuan teknologi yang pesat dan diiringi oleh kebutuhan transportasi yang semakin tinggi, manusia mulai mengembangkan tipe jembatan gantung, yaitu dengan memanfaatkan kabel-kabel baja. Tipe ini sangat bermanfaat pada bentang jembatan yang sangat panjang.

\section{Jembatan beton (concrete bridge)}

Beton telah banyak digunakan dalam dunia konstruksi. Saat ini, dengan kemajuan teknologi memungkinkan didapatkan jembatan dari beton yang beragam.

\section{Jembatan haubans/cable stayed}

Jembatan tipe ini sangat baik dan menguntungkan bila digunakan untuk jembatan bentang panjang. Kombinasi penggunaan kabel dan dek beton prategang merupakan keunggulan tipa ini

Bangunan atas jembatan adalah bagian struktur jembatan yang menerima langsung beban lalu lintas diatasnya. Beban lalu lintas tersebut dapat berupa kendaraan bermotor atau pejalan kaki. Bangunan atas yang umumnya terdiri dari atas:

\section{Gelagar}

Gelagar induk, terbentang dari titik tumpu sampai titik tumpu lainnya. Gelagar jembatan akan mendukung semua beban yang bekerja pada jembatan. Bahan gelagar berupa bahan kayu dan atau profil baja berupa profil kanal, profil $\mathrm{H}$ atau profil I

\section{Konstruksi tumpuan diatas pangkal jembatan (perletakan)}

Perletakan adalah bagian dari jembatan yang berada diantara bangunan atas dan bangunan bawah jembatan yang berfungsi untuk meneruskan beban dan gerakan antara bangunan atas dan bangunan bawah. 


\section{Konstruksi lantai kendaraan.}

Pelat lantai kendaraan ialah konstruksi yang menerima beban langsung dari kendaraan dan berfungsi meneruskan beban ke balok. Lantai jembatan berfungsi sebagai lantai untuk lalu lintas, merupakan, balok yang disusun sedemikian sehingga mampu mendukung beban. Biasanya dipasang dalam arah melintang jembatan, diatas gelagar.

\section{Diaphragma}

Diapragma adalah balok yang berada diantara dua gelagar yang berfungsi sebagai pengikat antar gelagar dan penyebaran beban hidup.

\section{Tiang Sandaran dan Trotoar}

Tiang sandaran merupakan kelengkapan jembatan yang berfungsi untuk keselamatan sekaligus untuk membuat struktur lebih kaku. Tiang sandaran umumnya direncanakan dengan tinggi $\pm 90-100 \mathrm{~cm}$ dari muka trotoar.Sedangkan trotoar biasa dibuat dan bisa tidak, tergantung perencanan. Secara umum, lebar trotoar minimum adalah untuk simpang 2 orang $( \pm 100-150 \mathrm{~cm})$ dan trotoar dibuat lebih tinggi $20-25 \mathrm{~cm}$ dari lantai jembatan. Satu hal yang perlu mendapatkan perhatian adalah saluran/ pipa drainase pada jembatan, guna mendrain genangan yang ada pada jembatan terutama bila lantai diberi lapis aus.

\section{HASIL DAN PEMBAHASAN}

Tabel 1. Data konstruksi

Tebal slab lantai jembatan
Tebal lapis aspal
Tebal genagan air hujan
Jarak antara girder baja
Lebar jalur lalu lintas
Lebar trotoar
Lebar total jembatan
Panjang bentang jembatan

$\begin{aligned} \mathrm{h} & = & & 0,25 \mathrm{~m} \\ \mathrm{ta} & = & & 0,05 \mathrm{~m} \\ \mathrm{th} & = & & 0,05 \mathrm{~m} \\ \mathrm{~s} & = & & 1,60 \mathrm{~m} \\ \mathrm{~b} 1 & = & & 5,50 \mathrm{~m} \\ \mathrm{~b} 2 & = & & 1,00 \mathrm{~m} \\ \mathrm{~b} & = & & 7,50 \mathrm{~m} \\ \mathrm{~L} & = & & 30,00 \mathrm{~m}\end{aligned}$

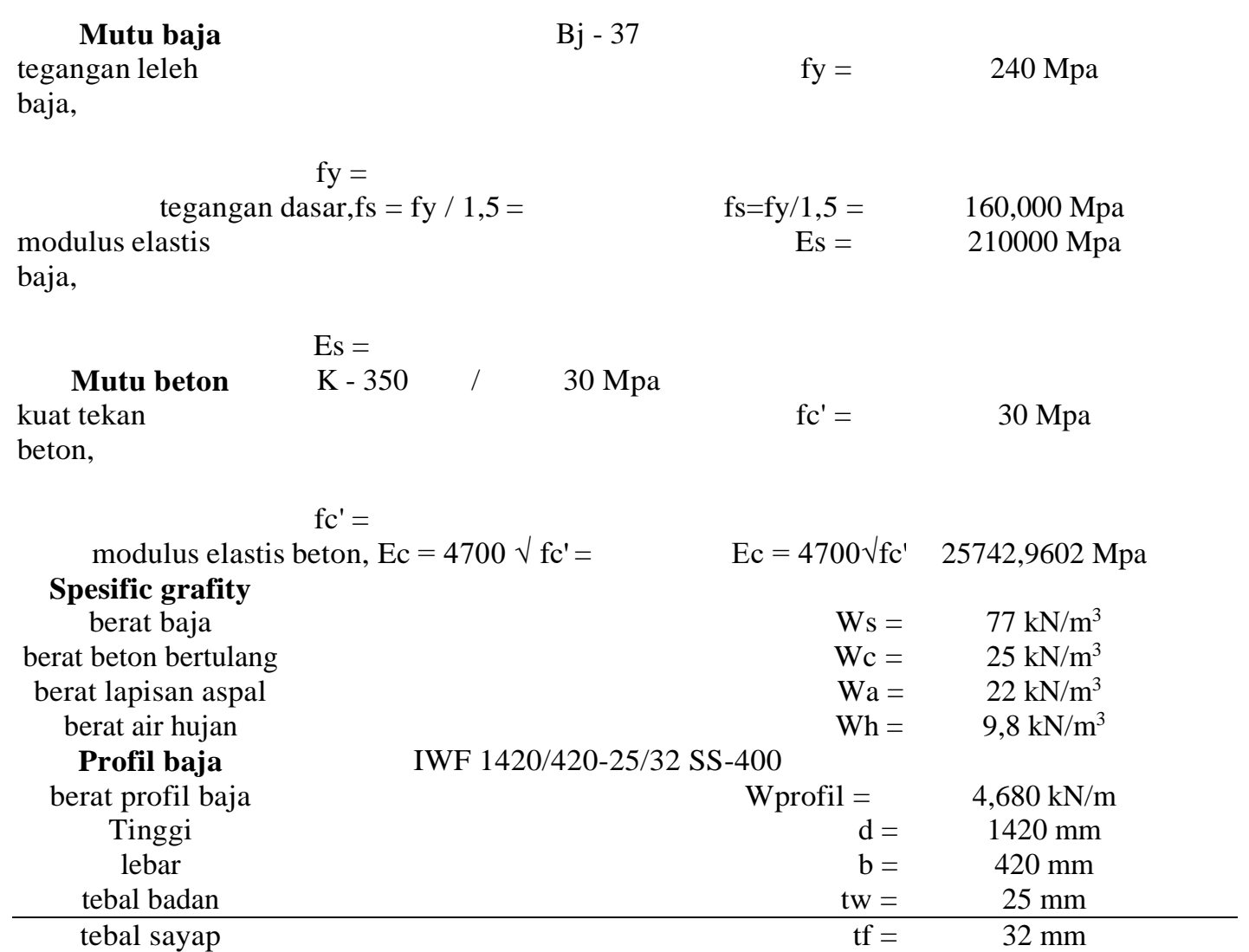




\begin{tabular}{ccc} 
luas penampang & $\mathrm{A}=$ & $60780 \mathrm{~mm}^{2}$ \\
tahanan momen & $\mathrm{Wx}=$ & $30146820,00 \mathrm{~mm}^{3}$ \\
momen inersia & $\mathrm{Ix}=$ & $18143098640,00 \mathrm{~mm}^{3}$ \\
panjang bentang & $\mathrm{L}=$ & $30000 \mathrm{~mm}$ \\
girder & $\mathrm{h}=$ & $250 \mathrm{~mm}$ \\
tebal slab beton & $\mathrm{s}=$ & $1600 \mathrm{~mm}$ \\
jarak antara girder & \\
\hline
\end{tabular}

Sumber: hasil perhitungan, 2020

\subsection{Section Properties Sebelum Komposite}

\section{Kontrol Penampang}

$\begin{array}{ll}\mathrm{L} / \mathrm{d} & =21,127 \\ 1,25^{*} \mathrm{~b} / \mathrm{tf} & =16,40625 \\ \mathrm{~L} / \mathrm{d} & >1,25 * \mathrm{tf} \text { OK/Yes } \\ \mathrm{d} / \mathrm{tw} & =56,800 \\ \mathrm{~d} / \mathrm{tw} & <75 \mathrm{OK} / \mathrm{Yes} \\ \text { Compact Section }(\mathrm{ok})\end{array}$

\section{Tegangan Ijin KIP}

Pada Girder baja diberi pengaku samping yg berupa balok diafragma yg berfungsi sebagai pengaku samping yg merupakan dukungan lateral dengan jarak,

$$
\begin{array}{ll}
\mathrm{L} 1=\mathrm{L} / 5 & =6000 \mathrm{~mm} \\
\mathrm{C} 1=\mathrm{L} 1 * \mathrm{~d} /(\mathrm{b} * \mathrm{tf}) & =633,92857 \\
\mathrm{C} 2=0,65 * \mathrm{Es} / \mathrm{Fs} & =853,125
\end{array}
$$

Karena nilai, $250<\mathrm{C} 1<\mathrm{C} 2$ maka :Tegangan Kip dihitung dengan rumus :

$\begin{aligned} \text { Fskip } & =\mathrm{fs}-(\mathrm{C} 1-250) /(\mathrm{C} 2-250) * 0,3 * \mathrm{fs} \\ & =129,445 \mathrm{Mpa}\end{aligned}$

$$
=129,445 \mathrm{Mpa}
$$

\section{Lebar Efektif Slab Beton}

Lebar efektif slab beton ditentukan dari nilai terkecil berikut ini :

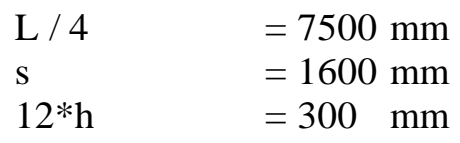

Diambil lebar efektif slab beton

$$
\mathrm{Be}=1600 \mathrm{~mm}
$$

\subsection{Section Properties Girder Komposit}

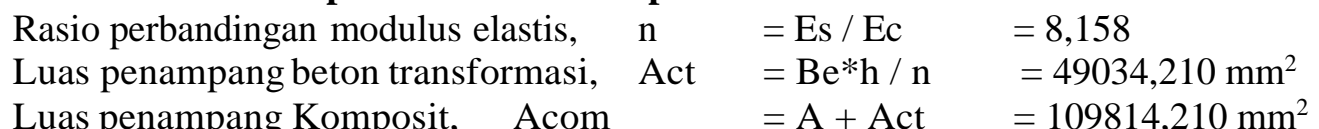

Momen statis penampang terhadap sisi bawah balok,

Acom $*$ ybs $=\mathrm{A} * \mathrm{~d} / 2+$ Act $*(\mathrm{~d}+\mathrm{h} / 2)$

Jarak garis netral terhadap sisi bawah,

$$
\begin{aligned}
\mathrm{ybs} & =(\mathrm{A} * \mathrm{~d} / 2+\mathrm{Act} *(\mathrm{~d}+\mathrm{h} / 2)) / \text { Acom } \\
& =1082,843964 \mathrm{~mm}
\end{aligned}
$$

$<$ d maka garis netral di bawah slab beton

Jarak sisi atas profil baja thdp garis netral, $\quad$ yts $\quad=\mathrm{d}-\mathrm{ybs} \quad=337,156 \mathrm{~mm}$

$$
\text { Jarak sisi atas slab beton terhadap garis netral, ytc } \quad=\mathrm{h}+\mathrm{yts} \quad=587,156 \mathrm{~mm}
$$

Momen Inersia penampang komposit :

$1 / 2 * \mathrm{Be}^{*} \mathrm{~h}^{\wedge} 3 / \mathrm{n} \quad=1532319060 \mathrm{~mm}$

Act $*(\mathrm{ytc}-\mathrm{h} / 2)^{\wedge} 2=10473128733 \mathrm{~mm}$ 
Ix

$$
\begin{array}{ll}
\text { Ix } & =18143098640 \mathrm{~mm} \\
\mathrm{~A} *(\mathrm{~d} / 2-\mathrm{yts})^{\wedge} 2 & =8449187113 \mathrm{~mm}
\end{array}
$$$$
\text { Icom } \quad=38597733546 \mathrm{~mm}
$$

Tahanan momen penampang komposite :

sisi atas beton, Wtc = Icom / ytc $=65736757 \quad \mathrm{~mm}^{3}$

Sisi atas baja, Wts $=$ Icom $/ \mathrm{yts} \quad=114480327,7 \mathrm{~mm}^{3}$

Sisi bawah baja, Wbs $=\mathrm{Icom} / \mathrm{ybs}=35644779 \mathrm{~mm}^{3}$

\section{Tegangan Ijin}

Tegangan ijin lentur beton $\mathrm{Fc}=0,4 * \mathrm{fc}^{\prime}$

Tegangan ijin lentur baja, Fs $=0,8 *$ fs

$$
\begin{aligned}
& =12 \mathrm{Mpa} \\
& =128 \mathrm{Mpa}
\end{aligned}
$$

\subsection{Kondisi Girder Sebelum Komposite Beban Sebelum Komposit}

Tabel 2. Beban sebelum komposit

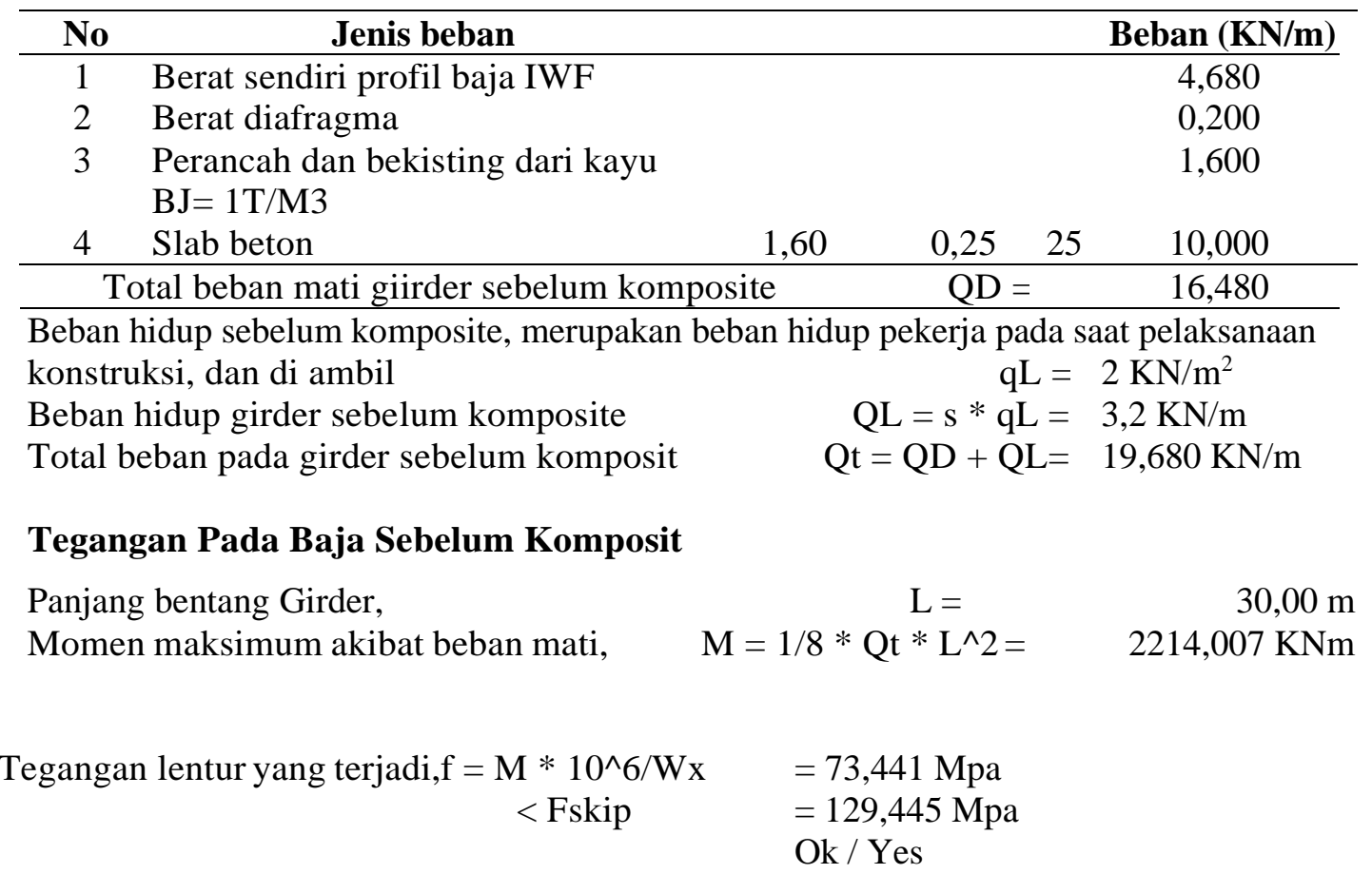

\section{Lendutan Pada Baja Sebelum Komposit}

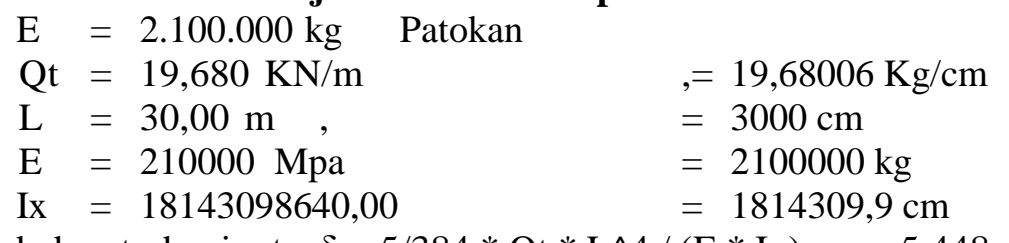

beban terbagi rata, $\delta=5 / 384 * \mathrm{Qt} * \mathrm{~L}^{\wedge} 4 /(\mathrm{E} * \mathrm{Ix}) \quad=5,448=0,054 \mathrm{~m}$

$<\mathrm{L} / 240 \quad=12,5 \mathrm{~cm}$

Ok / Yes 


\subsection{Beban Pada Girder Komposit Berat Sendiri (ms)}

Tabel 3. Berat Sendiri (ms)

\begin{tabular}{|c|c|c|c|c|}
\hline No & \multicolumn{3}{|c|}{ Jenis Konstruksi } & $\overline{\text { Beban }(\mathrm{KN} / \mathrm{m})}$ \\
\hline 1 & \multicolumn{3}{|c|}{ Berat sendiri profil baja IWF } & 4,680 \\
\hline 2 & \multicolumn{3}{|l|}{ Berat diafragma } & 0,200 \\
\hline 3 & Slab beton & 0,25 & 25 & 10,000 \\
\hline \multicolumn{3}{|c|}{ Total berat sendiri } & & 14,880 \\
\hline
\end{tabular}

Sumber: hasil perhitungan, 2020

Panjang Bentang girder, $\quad \mathrm{L}=30 \mathrm{~m}$

Momen dan gaya geser maksimum akibat berat sendiri

$$
\begin{aligned}
\mathrm{Mms} & =1 / 8 * \mathrm{Qms} * \mathrm{~L}^{\wedge} 2 & & =1674,0068 \mathrm{KNm} \\
\mathrm{Vms} & =1 / 2 * \mathrm{Qms} * \mathrm{~L} & & =223,2009 \mathrm{KN}
\end{aligned}
$$

\section{Berat Mati Tambahan (ma)}

Tabel 4. Berat Mati Tambahan (ma)



Sumber: hasil perhitungan, 2020

Panjang Bentang girder, $\quad \mathrm{L}=30 \mathrm{~m}$

Momen dan gaya geser maksimum akibat beban mati tambahan

$$
\begin{aligned}
& \mathrm{Mms}=1 / 8 * \mathrm{Qms}^{*} \mathrm{~L}^{\wedge} 2 \quad=286,2 \mathrm{KNm} \\
& \mathrm{Vms}=1 / 2 * \mathrm{Qms} * \mathrm{~L} \quad=38,16 \mathrm{KN}
\end{aligned}
$$

\section{Beban Lajur "D"}

Beban kendaraan yang berupa beban lajur "D" terdiri beban terbagi rata (Uniformly Distributed Load). UDL dan beban garis (Knife Edge Load), KEL seperti pada gambar UDL mempunyai intensitas q (kPa) yang besarnya tergantung pada panjang total $\mathrm{L}$ yang dibebani lalu lintas atau dinyatakan dengan rumus sebagai berikut :

$$
\begin{array}{ll}
\mathrm{q}=8,0 \mathrm{kPa} & \text { untuk } \mathrm{L} \leq 30 \mathrm{~m} \\
\mathrm{q}=8,0 *(0,5+15 / \mathrm{L}) & \mathrm{kPa} \quad \text { untuk } \mathrm{L} \leq 30
\end{array}
$$

KEL mempunyai intensitas, $\quad \mathrm{p}=<50 \mathrm{~m}$

Faktor beban dinamis (Dinamic Load Allowance) untuk KEL diambil sebagai berikut: DLA =
0,4
DLA $=0,4-0,0025 *(\mathrm{~L}-50)$
untuk $\mathrm{L}=<50 \mathrm{~m}$
DLA $=0,3$
untuk $50<\mathrm{L}<90 \mathrm{~m}$
untuk $\mathrm{L} \Rightarrow 90 \mathrm{~m}$

Panjang bentang girder, $\mathrm{L}=30 \mathrm{~m}$

$$
\mathrm{q}=\quad 8,000 \mathrm{Kpa} \quad \text { DLA }=0,4 \mathrm{~s}=1,60 \mathrm{~m}
$$

Beban lajur "D" $\quad$ Qtd $=q^{*} \mathrm{~s}=12,800 \mathrm{KN} / \mathrm{m}$

$\operatorname{Ptd}=(1+$ DLA $) * \mathrm{p} * \mathrm{~s}=98,56 \mathrm{KN}$

Momen dan gaya geser maksimum akibat beban lajur D

$$
\begin{array}{cl}
\mathrm{Mms}=1 / 8 * \mathrm{Qms}^{*} \mathrm{~L}^{\wedge} 2 & =72,640 \mathrm{KNm} \\
\mathrm{Vms}=1 / 2 * \mathrm{Qms} * \mathrm{~L} & =241,28 \mathrm{KN}
\end{array}
$$




\subsection{Gaya Rem (tb)}

Pengaruh pengereman dari lalu-lintas diperhitungkan sebagai gaya dalam arah memanjang dan dianggap bekerja pada jarak $1,8 \mathrm{~m}$ dari permukaan lantai jembata. Besarnya gaya rem tergantung panjang total jembatan $(\mathrm{Lt})$ sebagai berikut:
Gaya rem, $\mathrm{Ttb}=250 \mathrm{KN}$
Gaya rem, $\mathrm{Ttb}=250+2,5$ *
$(\mathrm{Lt}-80) \mathrm{KN}$ Gaya rem, Ttb
$=500 \mathrm{KN}$
Panjang bentang girder,
Jumlah girder,
Besarnya gaya rem,
Lengan terhadap pusat tampang
girder,
untuk $\mathrm{Lt}=<80 \mathrm{~m}$
untuk $80<\mathrm{Lt}<$
$180 \mathrm{~m}$ untuk $\mathrm{Lt}=>$
$180 \mathrm{~m}$
$\mathrm{L}=$
$\mathrm{n}=$
$\mathrm{Ttb}=250 / \mathrm{n}=$
$\mathrm{y}=\mathrm{ytc}+\mathrm{ta}+1,8=$
$30,00 \mathrm{~m}$
4
$62,5 \mathrm{KN} / \mathrm{m}$
7,722

Momen dan gaya geser maksimum akibat beban lajur D
$\mathrm{Mms}=1 / 8 * \mathrm{Qms}^{*} \mathrm{~L}^{\wedge} 2$
$=241,299 \mathrm{KNm}$
$\mathrm{Vms}=1 / 2 * \mathrm{Qms} * \mathrm{~L}$
$=16,28 \mathrm{KN}$

\subsection{Beban Angin (ew)}

Beban garis merata tambahan arah horizontal pada permukaan lantai jembatan akibat angin yg meniup kendaraan di atas jembatan dihitung dengan rumus:

$$
\text { Tew }=0,0012 * \mathrm{Cw} *(\mathrm{Vw})^{\wedge} 2 \quad \mathrm{KN}
$$

Koefisien seret,

$$
\mathrm{CW}=1,2
$$

Kecepatan angin,

$$
\mathrm{Vw}=35 \mathrm{~m} / \mathrm{det}
$$

Tew $=0,0012 * \mathrm{Cw} *(\mathrm{Vw})^{\wedge} 2=1,764 \mathrm{KN}$

Bidang vertical yg ditiup angin merupakan bidang samping kendaraan dengan

tinggi di atas lantai jembatan

jarak antara roda kendaraan

$$
\begin{aligned}
& \mathrm{h}=2 \mathrm{~m} \\
& \mathrm{x}=1,75 \mathrm{~m}
\end{aligned}
$$

tranfer beban angin ke lanyai jembatan Qew $=(1 / 2 * \mathrm{~h} / \mathrm{X} *$ Tew $)$

$$
\mathrm{Qew}=1,008 \mathrm{KN} / \mathrm{m}
$$

Momen dan gaya geser maksimum akibat beban angin,

$$
\begin{aligned}
& \mathrm{Mms}=1 / 8 * \mathrm{Qms}^{*} \mathrm{~L}^{\wedge} 2 \quad=113,4 \mathrm{KNm} \\
& \mathrm{Vms}=1 / 2 * \mathrm{Qms} * \mathrm{~L} \quad=15,12 \mathrm{KN}
\end{aligned}
$$

\subsection{Gaya Gempa (eq)}

Gaya gempa vertical pada balok dihitung dgn menggunakan percepatan vertical ke bawah sebesar $0,1 * \mathrm{~g}$ dengan $\mathrm{g}=$ percepatan gravitasi.

Gaya gempa vertical rencana: $\quad$ Tew $=0,10 * \mathrm{Wt}$

$\mathrm{Wt}=$ Berat total struktur yang berupa berat sendiri dan berat beban mati tambahan

Beban berat sendiri,

Beban mati tambahan,

\begin{tabular}{|c|c|}
\hline Wtc & $=65736757$ \\
\hline Wts & $=114480327,7$ \\
\hline Wbs & $=35644779$ \\
\hline $\mathrm{n}$ & $=8,158$ \\
\hline
\end{tabular}

Beban gempa vertikal,

Panjang bentang girder,

Qms $=14,880 \mathrm{KN} / \mathrm{m}$

$\mathrm{Qma}=2,544 \mathrm{KN} / \mathrm{m}$

Momen dan gaya geser maksimum akibat tranfer beban angin

$$
\begin{aligned}
& \mathrm{Mms}=1 / 8 * \mathrm{Qms}^{*} \mathrm{~L}^{\wedge} 2 \\
& \mathrm{Vms}=1 / 2 * \mathrm{Qms} * \mathrm{~L} \\
& =196,021 \mathrm{KNm} \\
& =26,136 \mathrm{KN}
\end{aligned}
$$

\subsection{Tegangan Pada Girder}


Tegangan pada sisi atas beton, Tegangan pada sisi atas baja, Tegangan pada sisi bawah baja,

$$
\begin{aligned}
& \mathrm{fts}=\mathrm{M} * 10^{\wedge} 6 /(\mathrm{n} * \mathrm{Wtc}) \\
& \mathrm{Fts}=\mathrm{M} * 10^{\wedge} 6 / \mathrm{Wts} \\
& \mathrm{Fbs}=\mathrm{M} * 10^{\wedge} 6 / \mathrm{Wbs}
\end{aligned}
$$

\begin{tabular}{|c|c|c|c|c|c|}
\hline \multirow[b]{2}{*}{ No } & \multicolumn{2}{|c|}{ Tegangan yg terjadi pada sisi } & \multirow{2}{*}{$\begin{array}{l}\text { atas beton } \\
\text { ftc } \\
(\mathrm{Mpa})\end{array}$} & \multirow{2}{*}{$\begin{array}{l}\text { atas baja } \\
\mathrm{fts} \\
(\mathrm{Mpa})\end{array}$} & \multirow{2}{*}{$\begin{array}{l}\text { bwh baja } \\
\text { fbs } \\
(\mathrm{Mpa})\end{array}$} \\
\hline & Jenis Beban & $\begin{array}{l}\text { Momen } \\
\mathrm{M}(\mathrm{KNm})\end{array}$ & & & \\
\hline 1 & $\begin{array}{l}\text { Berat } \\
(\mathrm{ms})\end{array}$ & 1674,007 & 3,122 & 14,623 & 46,964 \\
\hline 2 & $\begin{array}{l}\text { Beban mati } \\
\text { tambahan (ma) }\end{array}$ & 286,2 & 0,534 & 2,500 & 8,029 \\
\hline 3 & Beban lajur "D" & 72,640 & 0,135 & 0,635 & 2,038 \\
\hline 4 & Gaya rem (tb) & 241,299 & 0,450 & 2,108 & 6,770 \\
\hline 5 & Beban angin (ew) & 113,4 & 0,211 & 0,991 & 3,181 \\
\hline 6 & Beban empa (eq) & 196,021 & 0,366 & 1,712 & 5,499 \\
\hline
\end{tabular}

Tabel 5. Tegangan pada girder

Sumber: hasil perhitungan, 2020

\subsection{Perhitungan Shear Connector}

Gaya geser maksimum rencana, Vmax $=1671,492 \mathrm{KN}$

$\mathrm{ytc}=587,156 \mathrm{~h}=250 \mathrm{~mm}$

Luas statis penampang tekan beton yang ditranformasikan, A

Act $=49034,210 \mathrm{~mm}^{2}$

Momen statis penampang tekan beton yang ditranformasikan

Sc $=$ Act $*(y t c-h / 2)=22661456,1 \mathrm{~mm}^{3}$

Gaya geser maksimum, qmax $=\mathrm{Vmax} * \mathrm{Sc} / \mathrm{Icom}=981,3642102 \mathrm{~N} / \mathrm{mm}$

Untuk shear connector digunakan besi beton U, D 22

Luas penampang geser, Asv $=\prod / 4 * \mathrm{D}^{\wedge} 2 * 2=759,88 \mathrm{~mm}$

Tegangan ijin geser, $\mathrm{fsv}=0,6 * \mathrm{fs}=96 \mathrm{Mpa}$

Kekuatan satu buah shear connector, Qsv = Asv * fsv =72948,48 N

Jumlah shear connector dari tumpuan sampai 1/4 L :

$\mathrm{n}=1 / 4 * \operatorname{qmax} * \mathrm{~L} / \mathrm{Qsv}=100,896298$ buah

Jarak antara shear connector, $\mathrm{s}=\mathrm{L} /(4 * \mathrm{n})=74,33374811 \mathrm{~mm}$

Digunakan shear connector, D 22 - $70 \mathrm{~mm}$

Jumlah shear conector $1 / 4 \mathrm{~L}$ sampai tengah bentang :

$\mathrm{n}=1 / 8 *$ qmax $* \mathrm{~L} / \mathrm{Qsv}=50,448149$ buah

Jarak antara shear connector, $\mathrm{s}=\mathrm{L} /(4 * \mathrm{n})=148,6674962 \mathrm{~mm}$

Digunakan shear connector, D22-140 mm

\section{KESIMPULAN}

Dari hasil penelitian dalam perencanaan struktur bangunan bawah jembatan diperoleh kesimpulan perencanaan dengan dimensi tebal slab lantai jembatan direncanakan tebal 0,25 m, tebal lapis aspal direncanakan tebal $0,05 \mathrm{~m}$, tebal genagan air hujan direncanakan tebal 0,05 m, jarak antara girder baja direncanakan 1,60 m, lebar jalur lalu lintas direncanakan $5,50 \mathrm{~m}$, lebar trotoar direncanakan tebal 1,00 m, lebar total jembatan direncanakan 7,50 $\mathrm{m}$ dan panjang jembatan direncanakan bentang 30,00 m

\section{SARAN}

Perencanaan struktur harus sesuai dengan ketentuan dan persyaratan yang telah ditentukan dan berdasarkan ilmu keteknikan dibidang engineering khususnya ilmu teknik sipil.

Diharapkan untuk perencanaan struktur jembatan terutama struktur bangunan bawah jembatan merupakan suatu struktur yang terpenting yaitu struktur pangkal jembatan (abutment) dan pondasi, karena distribusi beban sepanjang bentang jembatan akan ditumpu oleh bagian pangkal jembatan (abutment) yang kemudian selanjutnya diteruskan pada bagian pondasi. 


\section{DAFTAR PUSTAKA}

Asiyanto, 2012. Metode Konstruksi Jembatan Beton. Universitas Indonesia-Press, Jakarta.

Aspaliza, N., Puluhulawa, I dan Armada. 2018. Perencanaan Struktur Atas Jembatan Komposit Sungai Nipah Desa Darul Aman Kecamatan Rupat, Jurnal Gradasi Teknik Sipil, Vol. 2, 1-9

Asiyanto, 2008. Metode Konstruksi Jembatan Rangka Baja. Universitas Indonesia-Press, Jakarta.

Badan Standarisasi Nasional, 2004. Perencanaan Struktur Beton Untuk Jembatan RSNI T-12-2004. BSN, Jakarta.

Badan Standarisasi Nasional, 2005. Perencanaan Pembebanan Jembatan RSNI T-02-2005. BSN, Jakarta.

Badan Standarisasi Nasional, 2016. SNI 1725 : 2016 Pembebanan untuk Jembatan. BSN, Jakarta.

Direktorat Jendral Bina Marga, 2005. Gambar Standar Pekerjaan Jalan dan Jembatan Volume Dua. Departement Pekerjaan Umum, Jakarta.

Direktorat Jendral Bina Marga, 1992. Bridge Design Manual. Departement Pekerjaan Umum, Jakarta.

Direktorat Jendral Bina Marga, 1992. Sistem Manajemen Jembatan - BMS - Peraturan Perencanaan Jembatan : Bagian 2 Beban Jembatan. Departement Pekerjaan Umum, Jakarta.

Dinas Pekerjaan Umum dan Penataan Ruang Kabupaten Serang. 2019. Laporan Antara DED Peningkatan Jembatan Rangkaspanjang Kecamatan Kragilan Kabupaten Serang, Tidak diterbitkan, Serang.

Dinas Pekerjaan Umum dan Penataan Ruang Kabupaten Serang. 2019. Laporan Pendahuluan DED Peningkatan Jembatan Rangkaspanjang Kecamatan Kragilan Kabupaten Serang, Tidak diterbitkan, Serang.

Dinas Pekerjaan Umum dan Penataan Ruang Kabupaten Serang. 2019. Laporan Antara DED Peningkatan Jembatan Rangkaspanjang Kecamatan Kragilan Kabupaten Serang, Tidak diterbitkan, Serang.

Dinas Pekerjaan Umum dan Penataan Ruang Kabupaten Serang. 2019. Laporan Akhir DED Peningkatan Jembatan Rangkaspanjang Kecamatan Kragilan Kabupaten Serang. Tidak diterbitkan, Serang.

Dinas Pekerjaan Umum dan Penataan Ruang Kabupaten Serang. 2019. Laporan Gambar DED Peningkatan Jembatan Rangkaspanjang Kecamatan Kragilan Kabupaten Serang, Tidak diterbitkan, Serang.

Dinas Pekerjaan Umum dan Penataan Ruang Kabupaten Serang. 2019. Laporan RAB DED Peningkatan Jembatan Rangkaspanjang Kecamatan Kragilan Kabupaten Serang, Tidak diterbitkan, Serang.

Gumilar, M.S dan Edrizky, M.R. 2017. Analisa Struktur Atas (Upper Structure) Jembatan Kaburejo Kota Pagar Alam, Jurnal Ilmiah Bering's, Vol. 4, 36-43.

Hardwiyono, S., Soebandono, B dan Hakim, L. 2013. Perencangan Ulang Struktur Atas Jembatan Gajah Wong Yogyakarta dengan Menggunakan Box Girder, Jurnal Ilmiah Semesta Teknika, Vol. 16, 10-20.

Hidayat, A.S dan Chayati, N. 2014. Perencanaan Struktur Atas Jembatan Beton Prategang, Jurnal Rekayasa Sipil Astonjadro, Vol. 3, 29-42

Puslitbang Prasarana Transportasi. 2005. RSNI T 03-2005. Perencanaan Struktur Baja untuk Jembatan, BSN Tidak diterbitkan, Bandung.

Soewartono, E. 2014. Perencangan Bangunan Atas Jembatan Mentikan di Kota Mojokerto dengan Menggunakan Metode Komposit, Jurnal Majapahit Techno, Vol. 4, 53-59.

Struyk, H. J.; Veen, K. H. C. W. V. D, dan Soemargono. 1990. Jembatan. Pradnya Paramita, Jakarta.

Supriyadi, B. dan Muntohar, A. S. 2007. Jembatan. Beta Offset, Yogyakarta.

Tamba, H., Yanti, G dan Megasari, S.W 2017. Perencangan Struktur Jembatan Beton Bertulang di Sungai Limapuluh Kota Pekanbaru, Jurnal Teknik, Vol. 1, Nomor 2, 58-65 